\title{
Aspects of energy efficiency in modern electrical installations
}

\author{
Maria Daniela Stochitoiu ${ }^{1 *}$, Ilie Utu ${ }^{1}$ \\ ${ }^{1}$ University of Petrosani, Department of A.C.I.E.E, 20 Street of University, Petrosani, Romania
}

\begin{abstract}
This paper emphasises that the implementation of energy efficiency concepts needs to take in consideration multiple aspects of applications, as it must preserve the level of functionality, safety and performance of the equipment and installations.
\end{abstract}

\section{Introduction}

The energy efficiency is one of the most cost-effective way to improve the security of supply, reduce energy-related emissions, assure affordable energy prices, and improve economic competitiveness. The international regulations context, efficiency standard IEC 60364-8-1 recommends the implementation of integrated management system of energy efficiency for low voltage electrical installations. The modern society has to exist in safety, clean and certain electrical energy supply as well as an energy efficiency using.

\section{Methods of energy efficiency increase}

\subsection{Common measures of energy efficiency increase}

The measures for increasing the energy efficiency are commonly classified as passive measures and active measures. Figure 1 outlines the classification of measures for improving energy efficiency. The values indicated in the figure are statistically determined. [1]

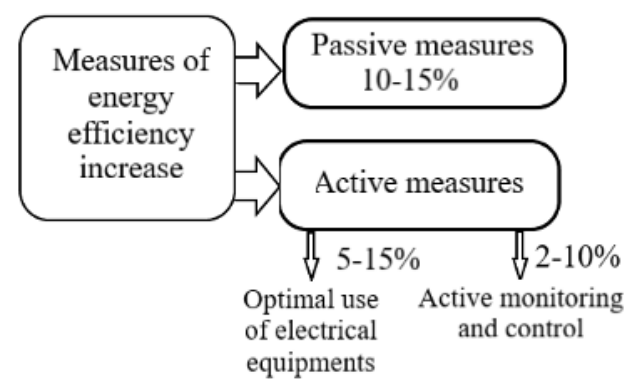

Fig.1 The main ways for improving the energy efficiency

\footnotetext{
*Corresponding author: danielastochitoiu@upet.ro
} 
The passive methods are the ones that target the decrease of Joule losses and the use the equipment with high energetic performance (with reduced nominal losses).

Some of the passive methods are: use of transformers and electrical motors with high efficiency (high nominal output), use of LED lighting, reducing the deforming regime through mounting the filters, use of batteries of capacitors for improving the power factor, or using the grid conditioners.

The active methods have the scope to implement an infrastructure for continuous measuring, monitoring and permanent control of energy consumption, which leads to maximum operating efficiency.

These active solutions for increasing of energy efficiency are divided in:

- methods for optimal use of system equipment like: use of frequency converters, soft starters and multifunctional relays for electrical drive controls (adapting the drive motors to the load), adjustment of system equipment to operate to its maximum output range, the automation of lighting circuitry control through use of various sensors.

- methods of monitoring and permanent control that involve its reactions of monitored parameters deflection: automate systems for power factor control; voltage regulators; predictive maintenance programmes (figure 2). [2]

Also, for optimisation of consumed electrical energy, the wireless communication between system`s equipment represents an active method in modern installations.

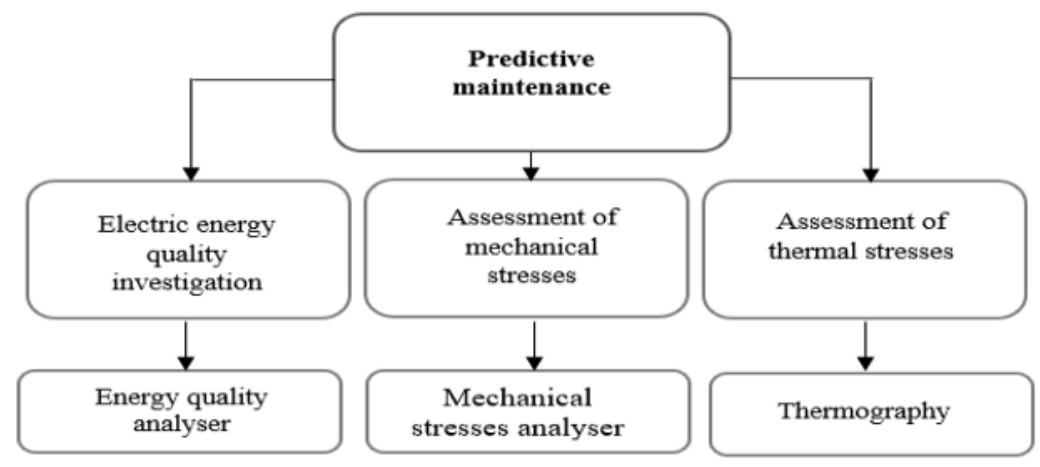

Fig.2 The main elements of predictive maintenance in electrical engineering

The energy efficiency does not mean only saving up energy without taking into account all other aspects involved, as the energy efficiency implementation has to preserve the level of functionality, safety and performances of the equipment and installations. The international regulations efficiency standard IEC 60364-8-1was developed for low voltage electrical installations (figure 3). [3]

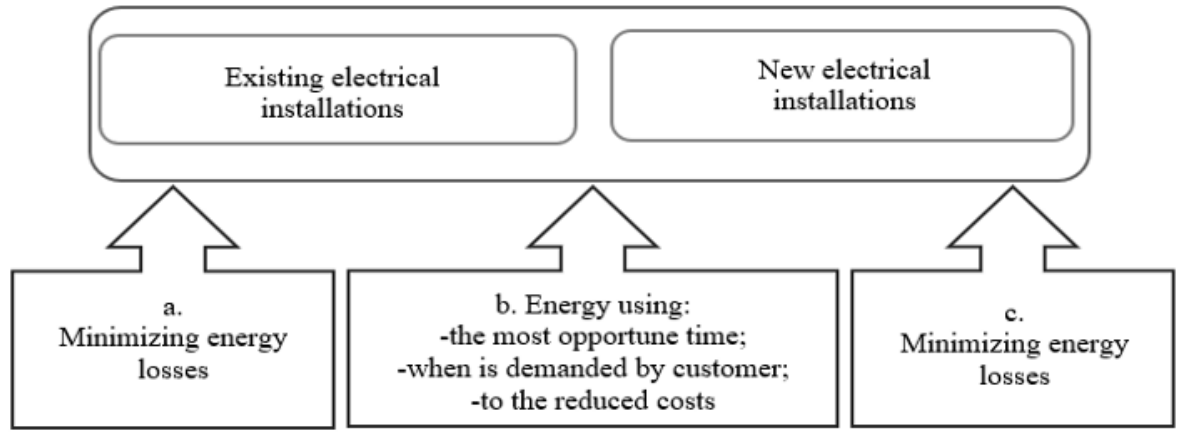

Fig.3 Implementation of international standard of energy efficiency for low voltage in electrical installations 
That imposed restrictions and recommendations for modern electrical installations design for ensuring a high energy efficiency and highlighting the importance of energy efficiency parameter in activity of design, construction, operating and maintenance of electrical installations. [4]

Energy efficiency is defined as the quantity of energy $(\mathrm{kWh})$ necessary per each unit produced, but for an electrical installation (into a building for e.g) the energy efficiency is defined through systemic approach as optimization of electrical energy considering:

- Minimisation of energy losses;

- Electrical energy use in opportune mode and to lower costs;

- Preserving the equipment's characteristics during the lifetime of installations.

The energy efficiency has to preserve the same level of operating, safety and performances for equipment into a technological line, the efficiency standard IEC 60364-81 recommends the implementation of integrated management system or energy efficiency based on:

- user setting of main parameters, including of non-electrical parameters;

-suitable selection of the available energy sources, to assure customers supply at lowest costs; -acquisition of available energy at hourly rates;

-acquisition of data related to energy quality;

-acquisition of data from the various sensors of installations (temperature, pressure, humidity)

-communication with user about information details related to energy consumption;

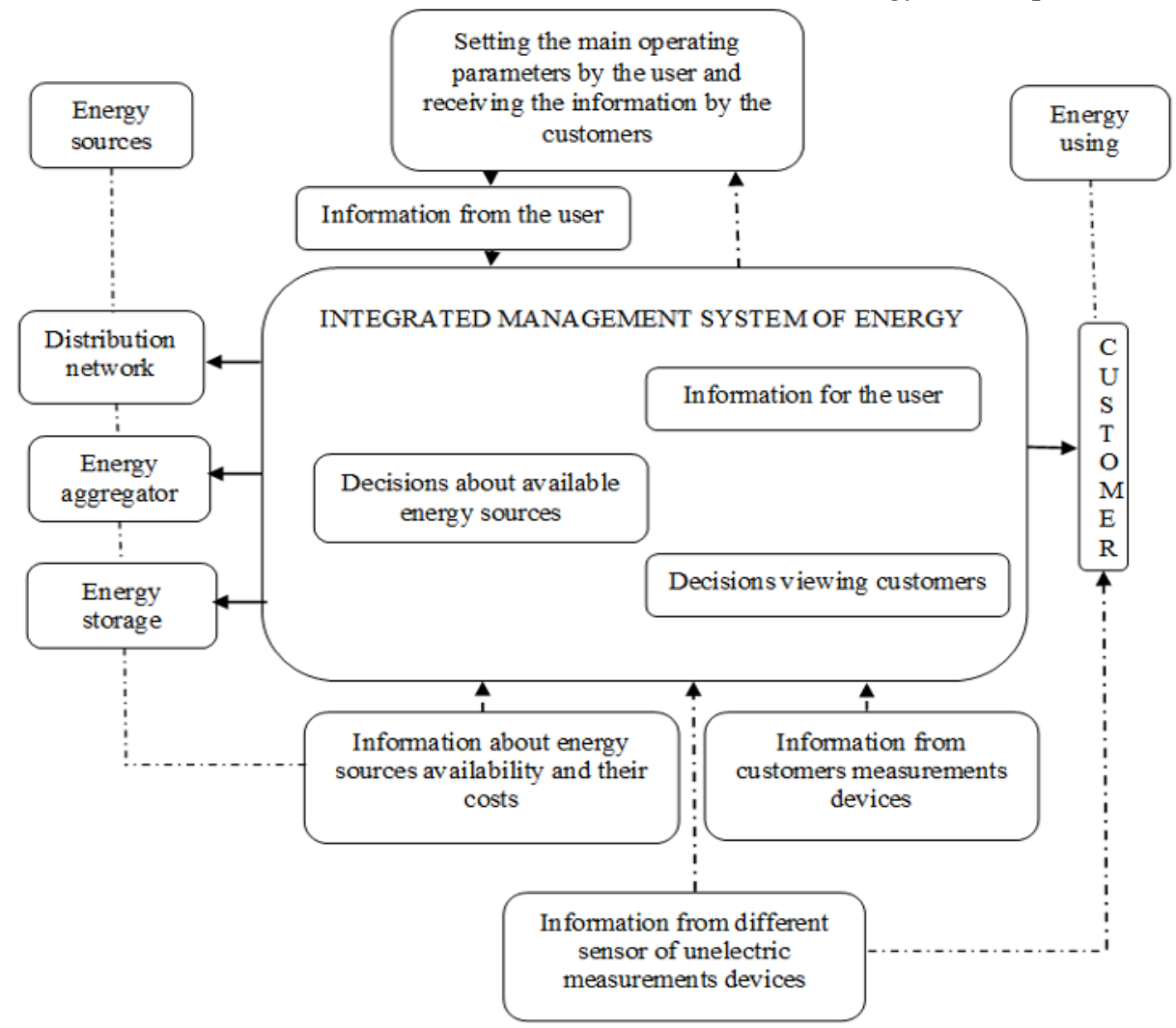

Fig.4 Implementation of integrated management system for energy efficiency 


\subsection{Energetical optimisation of electrical drives systems}

The development of new power electronics devices in parallel with using more and more information technology, has allowed the development of power converters with increased performances. Operating power converters in the electrical drives provides further opportunities for energy efficiency through adapting the operating parameters of the engine to the load and reduction of process losses. In the electrical drives with variable loads, operating these modern devices can account for 35\% reduction of energy losses (especially in the applications for adjusting the flow of fluids by changing the speed of pumps or ventilators). [5]

Without considering other measurements for decreasing energy consumption, there are two possible solutions:

- continuous monitoring of mechanical elements from drive system that can result in a low operational efficiency for electrical motor (for example a deviation of just $0,6 \mathrm{~mm}$ of the motor shaft from the axis of the load, increases the losses by $8 \%$ );

- development of methods of recovering the braking energy with the logistics organized measurement logistics. [1,6]

\subsection{Decreasing the deforming regime and power factor correction}

The choice of power factor correction equipment only has to achieve after the strict energy quality analysis for customers where compensation of the reactive power is necessary. Knowing the parameters of the power quality, such as, the level of voltage harmonics distortions and the absorbed current of receptor, are mandatory.

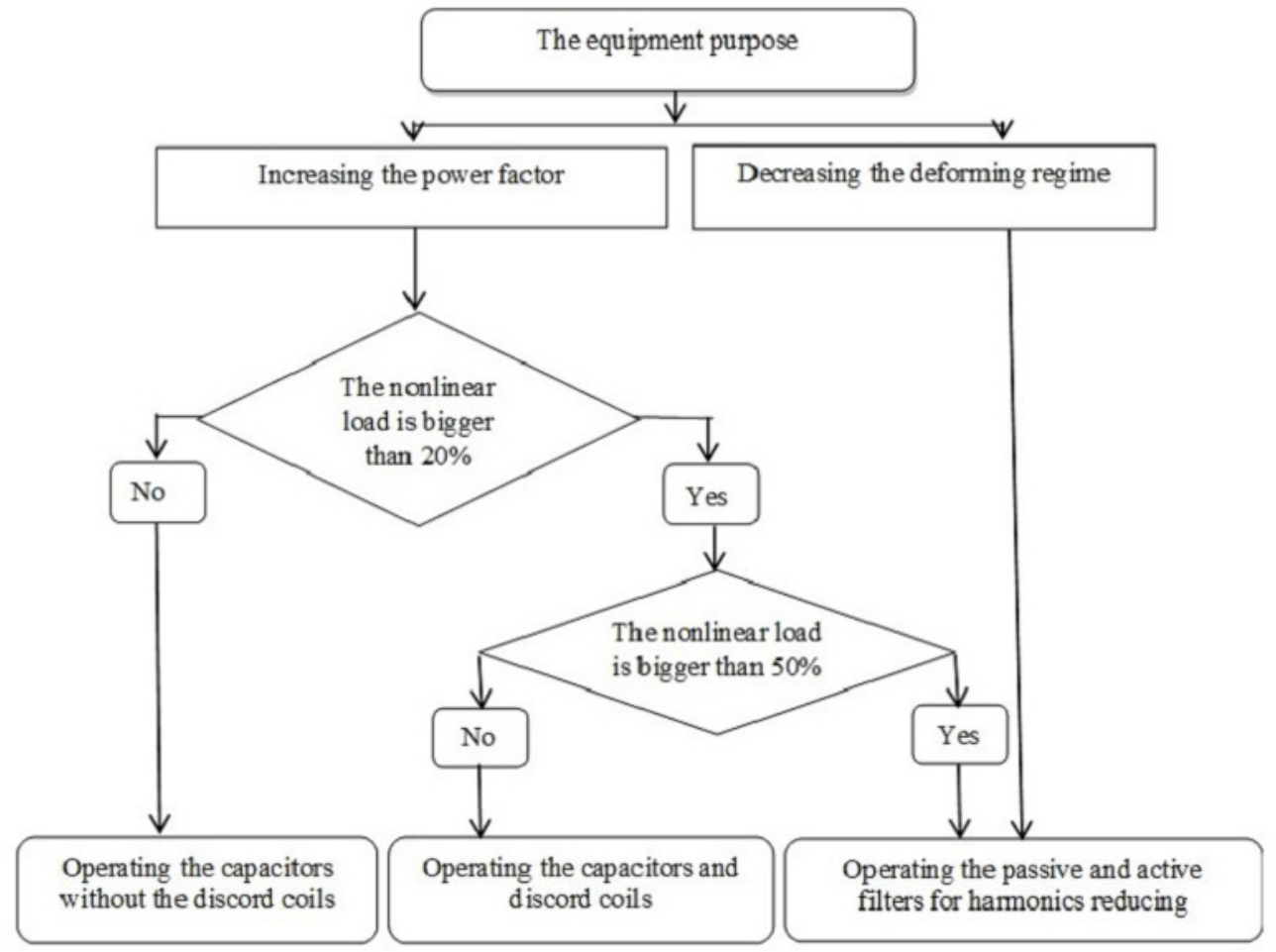

Fig.5 The fundamental selection for power factor correction and decreasing the deforming regime for equipment 
The above diagram shows the selection of this equipment based on customer characteristics (linear or nonlinear receptor) and the percentage of non-linear load of the customer. [7,8]

For power factor correction option in an installation where there are superior harmonics in current and voltage, the following methods are used:

- the deforming power setting method $[\mathrm{G}=$ the sum of the apparent power of all devices which determine harmonics (static converters, invertors, speed controls, LED lightings, etc.) and connected at the point of connection where the compensation device compensation; $\mathrm{S}_{\mathrm{T}}$ $=$ the sum of the apparent power of the supply transformers on the distribution bars.] This method can be applied only for limited level of THD (the Total Harmonic Distortion), as $\mathrm{THD}_{\mathrm{u}}<2 \%$ and $\mathrm{THD}_{\mathrm{i}}<30 \%$, and it needs to measure some parameters of power quality.

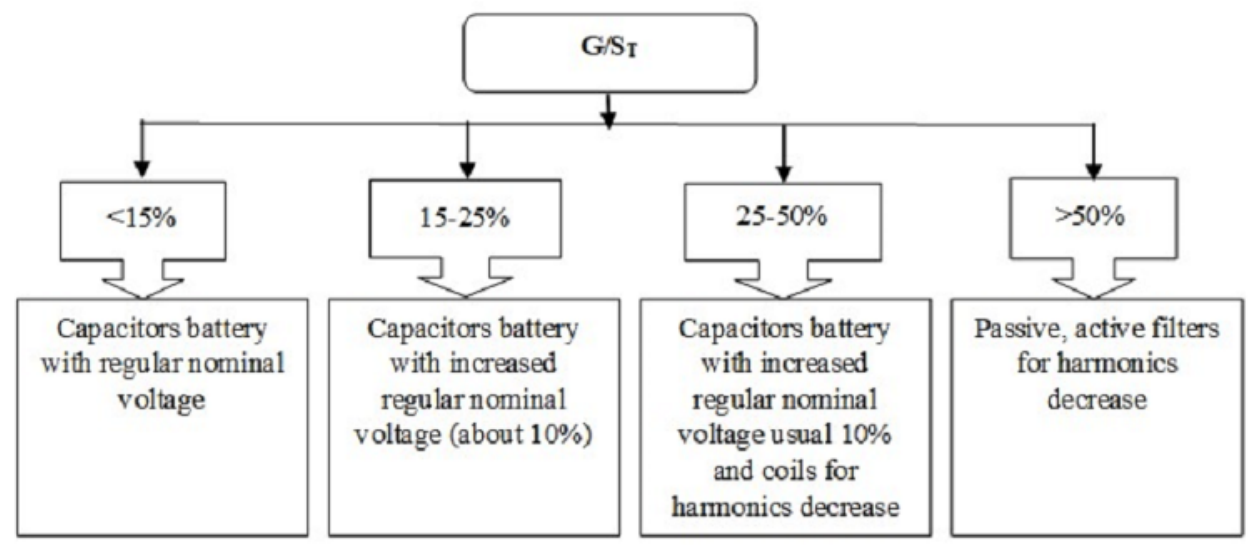

Fig. 6 The selection of reactive power factor

- the method for direct measurement of THDu and $\mathrm{THD}_{\mathrm{i}}$. This method considers following equipment: standard capacitors batteries, capacitors batteries with high nominal voltage (usual with $10 \%$ ), capacitors batteries with high nominal voltage and attenuation coils, passive and active filters for reducing harmonics.

It is very important that compensation capacitors to be disconnected in order to avoid resonances with harmonics and overload at high frequency current. [8]

\subsection{Optimal management of lighting system}

The international stats are showing that energy used for lighting of industrial domain is about $5 \%$ of total demanded electrical energy, so an adequate monitoring of lighting installations improves the energy efficiency for industrial system, through integral preservation of lighting parameters $[2,9]$. Nowadays, solutions for reducing the energy in lighting systems are based on passive methods as: efficient use of natural light, replacement of lighting bulbs with high performances bulbs, division of the lighting installation, and also on active methods such as: adaptive adjustment of artificial lighting level and monitoring of lighting using various sensors.

For highlighting the advantages of various types of bulbs used in industrial lighting and the energy efficiency, we can use the indicators shown in the below table.

The intelligent management of electrical lighting systems may allow reduction of electric energy consumption up to seventy percent, as lighting affects the power quality of the electrical distribution system through introduction of perturbances. 
Table 1. The main technical specification of different lighting types

\begin{tabular}{|l|c|c|c|c|}
\hline \multicolumn{1}{|c|}{ Light bulbs type } & $\begin{array}{c}\text { Nominal } \\
\text { power } \\
{[\mathbf{W}]}\end{array}$ & $\begin{array}{c}\text { Lighting } \\
\text { efficiency } \\
{[\mathbf{I m} / \mathbf{W}]}\end{array}$ & $\begin{array}{c}\text { Life time } \\
{[\mathbf{h}]}\end{array}$ & $\begin{array}{c}\text { Approximative } \\
\text { price } \\
{[\text { Euro] }}\end{array}$ \\
\hline Incandescent normal & $15-500$ & $8-20$ & 1000 & $0,32-0,45$ \\
Incandescent with halide & $75-2000$ & $20-30$ & 2000 & 4,0 \\
\hline Fluorescent & $15-140$ & $75-100$ & 1600 & 1,68 \\
Compact fluorescent light & $5-40$ & $55-88$ & 8000 & $14-18$ \\
Low pressure sodium & $18-180$ & $150-200$ & 8000 & $28-30$ \\
\hline Mercury & $100-2000$ & $32-60$ & 20000 & $15-18$ \\
High pressure sodium & $50-1000$ & $66-130$ & 24000 & $18-20$ \\
Metal halide & $70-1800$ & $60-110$ & 15000 & $18-20$ \\
\hline Induction lamps & $55-150$ & $65-70$ & 60000 & $210-300$ \\
\hline Compact induction lamps & 23 & 48 & 10000 & $15-20$ \\
\hline Light-emitting diodes & $1-75$ & $50-80$ & 80000 & $25-300$ \\
\hline
\end{tabular}

Bulbs are often referred to as lamps in many technical applications.

\subsection{The load management in the electrical grid}

The electrical distribution companies adjust the prices of supplied electrical energy to to encourage reduction of energy demand in the peak periods and synchronize the energy consumption with energy production. $[10,11]$

From prospective of responding to load demand, some strategies are adopted to accomplish this:

- demand restriction -the industrial consumers can achieve electrical energy savings up to $3 \%$;

- $\quad$ peak demand avoidance - the principle is based on reducing the costs while using the same amount of energy, but rather in off-peak time;

- load scheduling - hourly declaration of insignificant consumer`s operation having preferential rates

- additional on-site energy generation

For consumers, smart systems for managing the load were developed, such as smart load management and smart consumer for reducing the electrical energy costs.

\subsection{Use of smart panels}

Smart panels are modern distribution panels which allow measuring the main parameters of electrical energy quality and feature remote transmission using different communication protocols based on international standards, such as Wi-fi, Modbus, Industrial Ethernet, etc. The smart panels also transmit certain commands to the incorporated control devices (switching devices, adjustments, etc.). [4]

Even as the smart panels still have a high cost, they are available for a wide range of powers, offering opportunities to manage and control of consumers and their operating parameters.

The smart panels capabilities allow:

- $\quad$ interventions to assure a high energy efficiency;

- detection of peaks or abnormal consumptions of electrical energy;

- providing essential information for predictive maintenance;

- emphasis on energy consumption trends of electrical receivers in order to identify energy reduction opportunities. 


\subsection{Computer systems for monitoring, processing and communication of electrical data}

Information technologies has led to an increase of technologies efficiency due to developments in semiconductors and data storage in the last decades. Communication between industrial devices allows a lot of features such as: interrogation, command, remote control.

Communication systems are offering an active method of improving of energy efficiency in the industrial processes as: integration on the large scale of the automation processes, removal of defects in the system, reducing the breakdowns and assuring so the continuity in service. Supervisory Control and Data Acquisition is the most known solution through which the monitoring system simultaneously monitors voltages as well as power flow in transmission lines, while also fulfil the previously mentioned functions. [11]

Economic factors, as well as climate, govern the operation of systems and modern control techniques and management strategies emphasizing the current trends in the field, and also the influence of evolving energy balance on the environment. [12] It is necessary that the electrical systems be periodically audited by experts in quality and energy efficiency.

\section{Conclusions}

A general classification is necessary and the measures of increasing energy efficiency are divided in passive and active measures through: energetical optimisation of electrical drive systems; power factor correction correlated with decreasing the deforming regime; optimal manage of electric lighting system; using of smart electrical panels; computer system of monitoring control and data acquisition and smart load management.

\section{References}

1. E. Cazacu, L. Petrescu, Expertiza sistemelor electrice industriale (Printech, Bucuresti, 2014)

2. N. Golovanov, N. Mogoreanu, C. Toader, R. Porumb, Eficienta energetica. Mediul. Economia moderna (Agir, Bucuresti, 2017)

3. IEC 60364-8-1:2019, Low-voltage electrical installations - Functional aspects - Energy efficiency (2019)

4. Schneider Electric, Electrical installations Guide, 2018

5. F.G.Popescu, D.Pasculescu, M. Marcu, T. Niculescu, A.Handra, Annals of the University of Petrosani, 21, 2019

6. E. Cazacu, L. Petrescu, V. Ionita, Elemente de calitate si eficienta a energiei in instalatiile electrice modern (Matrixrom, Bucuresti, 2020)

7. Fluke 430 series II, Three Phase Power Quality and Energy Analysers Data Sheets

8. W. Just, W. Hofmann, Blindstrom compensation in der Betriebspraxis (VDE Verlag, Offenbach,2003)

9. D. Pasculescu, L.Pana, G. Buica, V. Pasculescu, R Dobra, Quality - Access to Success, Supplament 1, 20,6, (2019)

10. M.D. Stochitoiu, A.Handra, Annals of University of Petrosani, 20, 4, 2018

11. M.D Stochitoiu, I. Utu, Fundamente teoretice ale elementelor si instrumentelor de eficientizare a managementului energetic (Universitas, Petrosani, 2020)

12. http://www. ec.europa.eu/environnement [accessed 9.06.2021] 